\title{
Comparison Between Three Different Methods of Abdominal Entry in laproscopic gynaecologic surgery
}

\author{
M.A.Mohamed, B.E.Sakr, A.A.Aly and E.K.Esmail
}

Obstetrics and Gynecology, Dept., Faculty of Medicine, Benha Univ., Benha, Egypt

E-mail: ehabkamel131@yahoo.com

\begin{abstract}
Objective: To compare the three different laparoscopic entry methods: classic closed laparoscopy, left upper quadrant entry and open laparoscopy.

Patients and methods:75 patients underwent elective laparoscopic surgery at the Obstetrics and Gynecology department, benha university Hospital and private hospital after obtaining their informed consents .They were randomized in to three groups:

- $\quad 25$ patients were assigned to classic closed laparoscopy.

- $\quad 25$ patients were assigned to open laparoscopy .

- $\quad 25$ patients were assigned to left upper quadrant entry.

The main outcome measures were statistically compared: time required for entry into abdomen and occurrence of vascular and/or bowel injury. All patients had intraperitoneal view of the primary port site during surgical procedure. Results: Statistical differences, in favor of the classic closed laparoscopy and lef upper quadrant entry $(\mathrm{P}<.01)$, were found in duration of entry. The surgical complications in classic closed laparoscopy versus left upper quadrant entry versus open laparoscopy were not statistically different.Conclusion: In our study, the results of this comparison of entry methods suggest that Classic closed laparoscopy and Left upper quadrant entry a small clinical advantage over the Open laparoscopy in patients with previous abdomino pelvic surgery, in terms of saving time. The study also suggests the Classic closed laparoscopy and Left upper quadrant entry is easier in obese patients.
\end{abstract}

Keywords: laparoscopic entry, open laparoscopy, left upper quadrant entry, complications, adhesions, Veress needle, blind closed access.

\section{Introduction}

In laparoscopy, the abdominal cavity and its contents are examined by the use of a scope, from the Greek laparo-abdomen, scopein-to-look-at. A cannula is inserted through the abdominal wall, the abdominal cavity is filled with gas or air (pneumoperitoneum), and a lighted telescope is used to see and examine the abdomen's contents [1].

In the past several decades, laparoscopy has become a more common surgical method than laparotomy. When used for routine surgical and gynaecological treatments, laparoscopy reduces the size of the incision and the time it takes to heal, as well as the amount of discomfort patients experience [2].

Laparoscopic surgery, on the other hand, seems to have a reduced overall risk of complications than laparotomy [3].

A frequent surgical treatment in gynaecological medicine, laparoscopy has been the preferred way for treating benign disorders that need surgery during the last several decades $[4,5]$.

Laparoscopy in gynaecology has evolved over the last 30 years, from simple diagnostic procedures like tubal sterilisation to more complex procedures like the treatment of cancer [6].

Although laparoscopic surgery has made tremendous strides in the previous two decades, a laparoscopic procedure's first entrance still accounts for around $40 \%$ to $50 \%$ of all laparoscopic problems [7].

An evaluation of the most significant issues that occur during the laparoscopic access phase is especially essential in determining the safety of laparoscopy since many major complications arise during this phase [8].

However, most of these investigations were conducted by gynaecologists and general surgeons, with some reporting on the safety of laparoscopic procedures as well [9].

At least half of all serious difficulties in laparoscopy occur before the operation even begins, making the creation of the pneumoperitoneum the first and most crucial stage of the process. There has been no change in the incidence of complications during the last two decades [10].

Laparoscopy's principal trocar entrance method is still a contentious issue. One strategy will not work in every situation. In each situation, based on the thoroughness of the preoperative examination and the surgeon's expertise, the entry approach might be tailored. Multi-centric investigations are needed to ensure the safety and routine practicality of the various approaches under development [11].

It should be straightforward to learn, repeatable, cost-effective, and time-saving for patients of different sizes and backgrounds, including those who have had prior procedures and those who are overweight. In terms of the best procedure, no surgical or multidisciplinary agreement has been reached yet $[12$, 13].

Laparoscopy problems may be compared using three distinct entrance methods: closed, left upper quadrant, and open. The purpose of this research is to assess the rates of complications. 


\section{Patients and Methods}

\subsection{Study design}

Comparative prospective study. It included 75 patients underwent elective laparoscopic surgery at the Obstetrics and Gynecology department, Benha university Hospital and private hospital after obtaining their informed consents .The study was done starting from December 2020 till December 2021.

\section{They were randomized in to three groups:}

- Group A: including 25 patients assigned to classic closed laparoscopy.

- Group B: including 25 patients assigned to open laparoscopy.

- Group C: including 25 patients assigned to left upper quadrant laparoscopy.

\subsection{Inclusion criteria}

Patients were within their reproductive age indicated for diagnostic or operative laparoscopic procedures such as pelvic inflammatory disease, infertility, missed IUD, ectopic pregnancy and pelvic tumors.

\subsection{Exclusion criteria}

Patients with absolute contraindications for laparoscopy: past history of abdominal or pelvic tuberculosis, past history of puerperal sepsis, extremes of age .

\subsection{Methodology}

1) The following data were collected for each patient:

- Name and age.

- Indications of the procedure.

- History of previous laparotomies.

- History of endometriosis or PID.

- History of medical disorders.

- BMI was calculated: $\frac{\text { weight }}{\text { (height })^{2}}$

2) The following data were collected about the procedure:

- Type of procedure (diagnostic or operative).

- Type of entry.

- Size of trocars.

- Sites and number of surgical ports.

- Use of energy.

- Equipments' faults.

- Instrumental faults.

- Failure to complete the procedure.

- Intraoperative complications.

- Postoperative diagnosis.

All laparoscopic procedures were performed under general anesthesia. All women were given a prophylactic antibiotic. A naso gastric tube was inserted to decompress the stomach in group $\mathrm{C}$.

Throughout the investigation, advisors who were well-versed in the various methods of entry were used.

After raising the abdomen wall below the umbilicus for counter-traction, the Veress needle was introduced via a $3 \mathrm{~mm}$ sub umbilical skin incision at a 45-degree angle to the spine under closed laparoscopy (group A). It was at this place, anterior to the sacrum but below the bifurcation of the aorta and proximal parts of the vena cava, that a needle tip was inserted. Only a little portion of the needle's shaft was gripped by the tips of the fingers while it was steered into place, just enough so that its tip could enter the abdomen's peritoneum. Veress needle entrance was recognised by a double click sound, hiss test, lack of resistance, and verified by aspiration test, saline drop test, and initial intra-peritoneal pressure. Incision was widened to $1 \mathrm{~cm}$ following pneumoperitoneum, and a trocar $(10 \mathrm{~mm})$ was placed in the same direction after the abdomen was lifted. [11].

According to the patient and operation, the number, location, and size of various surgical ports were determined.

Two Allis forceps were used to evert the umbilicus in open laparoscopy (group B). A 10- to 15-mm-long vertical skin incision was made at the deepest part of the umbilicus. Using two Kocher forceps, the underlying fascia was lifted up, and a vertical midline slit was made in the fascia. Kocher or Allis forceps were used if the peritoneal cavity was still intact, and Metzenbaum scissors were used if it was not. After the 11-mm Hasson trocar was inserted, facial sutures were attached and fixed [14].

In the top left quadrant (group C). In order to relieve the pressure on the stomach, the patient was given general anaesthesia, and a nasogastric tube and Foley's catheter were put into the bladder. Slightly below the left costal margin, at the mid-clavicular line, a tiny skin incision was made 3 centimetres below the left costal margin. A Veress needle was introduced into the peritoneal cavity via the skin incision at a 45degree angle to the abdominal wall. It was achieved by inflating the abdomen with carbon dioxide until an abdominal pressure of $25 \mathrm{mmHg}$ was achieved. Laparoscopes were inserted into the abdomen and the abdomen was examined with a 0-degree laparoscope. The intra-abdominal pressure was lowered to $12 \mathrm{mmHg}$ throughout the procedure. Under direct observation, secondary ports were installed in the bottom quadrants. With or without the use of umbilical cannulas, surgical operations were carried out as planned [15].

All that was left of the abdominal cavity had been examined by means of a laparoscope, which was then inserted.

No additional surgical findings were examined; the research solely looked at laparoscopic entrance and compared conventional closed laparoscopy with left upper quadrant entry and open laparoscopy.

Quantitative data was used to assess the effectiveness of laparoscopic entry procedures, such as the time from incision to intra-abdominal viewing through the laparoscope and the incidence of significant vascular and intestinal damage.

Also documented were gas leakage, omental injury, instrument failures, equipment problems, and an entery failure. A minute's worth of time was allotted for admission. 


\subsection{Statistical Analysis}

Statistical analysis was conducted using SPSS $22^{\text {nd }}$ edition, numeric variables were presented in mean and standard deviation and compared using Kruskal Wallis test among study groups. Categorical variables were presented in frequency and percentages and compared using Chi-squared $\left(\chi^{2}\right)$ test. Any $\mathrm{p}$ value $<0.05$ was considered significant.

\section{Results}

Regarding the age, no significantly different values among Left upper quadrant group with $\mathrm{p}$ value 0.13, as well, BMI was significantly higher in Left upper quadrant group with $\mathrm{p}$ value 0.015 . While there was no difference between groups in terms of previous abdominal operations with p value 0.64 (Table 1).

In our present study, surgical complications were reported in 6 cases . 2 cases $(7.7 \%$ ) had gas leak in open entery port . 1 case had failure of entery due to obesity $(3.8 \%)$ in open entery technique , surgical exploration was done to perform ovarian cystectomy 1 case had failure due to adhesions (4.3\%) in left upper quadrant entery port . 2 cases $(7.7 \%)$ had omental injury which was affecting the greater omentum in both cases and it was managed by electrocoagulation of diathermy . There was no significant difference between the three groups as regard bowel injury, major vascular injury, equipment's faults as well as instrumental faults with p value $>0.05$ (Table 2).

Surgical site infection was only reportded in 2 cases in the Left upper quadrant group (Table 3).

Open approach had the longest time consumption for entry $13.6 \pm$ SD 3.1 minutes versus $2.6 \pm$ SD 1.2 minutes in closed type and 4.7 \pm SD 2.9 minutes in Left upper quadrant group (p value 0.0001) (Table 4).

There was a statistically significant difference among Close and open approached $p$ value 0.0001 and between Left upper quadrant and open with $\mathrm{p}$ value 0.0001 (Table 5 \& figure 1 ).

Table (1) comparison of demographics based on the type of entry among the included females.

\begin{tabular}{lccccc}
\hline Demographics & Type of entry & & $\begin{array}{c}\text { Test } \\
\text { statistics }\end{array}$ & P value \\
& $\begin{array}{c}\text { Closed } \\
(\mathbf{n = 2 5})\end{array}$ & $\begin{array}{c}\text { Open }(\mathbf{n = 2 5}) \\
\text { Left upper } \\
\text { quadrant }(\mathbf{n = 2 5})\end{array}$ & \\
\hline Age $($ years $)$ & $27.2 \pm 3$ & $27.1 \pm 3$ & $27.9 \pm 3$ & 9.55 & 0.13 \\
BMI $\left(\mathrm{Kg} / \mathrm{m}^{2}\right)$ & $27 \pm 2$ & $27 \pm 2$ & $29 \pm 2$ & 8.39 & 0.015 \\
Previous operations & $1.9 \pm 1.3$ & $1.5 \pm 1$ & $1.7 \pm 1.7$ & 2.2 & 0.64 \\
\hline
\end{tabular}

Kruskal Wallis test.

Table (2) comparison of intraoperative complications between three arms.

\begin{tabular}{|c|c|c|c|c|c|c|c|c|c|}
\hline \multirow[t]{3}{*}{ Parameter } & & \multicolumn{6}{|c|}{ Type of entry } & \multirow[t]{3}{*}{$\chi^{2}$} & \multirow[t]{3}{*}{$P$ value } \\
\hline & & \multicolumn{2}{|c|}{ Closed $(n=25)$} & \multicolumn{2}{|c|}{ Open $(n=25)$} & \multicolumn{2}{|c|}{$\begin{array}{c}\text { Left upper } \\
\text { quadrant }(n=25)\end{array}$} & & \\
\hline & & $\mathbf{N}$ & $\%$ & $\mathbf{N}$ & $\%$ & $\mathbf{N}$ & $\%$ & & \\
\hline \multirow[t]{2}{*}{ Equipment's faults } & No & 25 & $100.0 \%$ & 25 & $100.0 \%$ & 25 & $100.0 \%$ & NA & NA \\
\hline & Yes & 0 & $0.0 \%$ & 0 & $0.0 \%$ & 0 & $0.0 \%$ & & \\
\hline \multirow[t]{2}{*}{ Instrumental faults } & No & 25 & $100.0 \%$ & 25 & $100.0 \%$ & 25 & $100.0 \%$ & NA & NA \\
\hline & Yes & 0 & $0.0 \%$ & 0 & $0.0 \%$ & 0 & $0.0 \%$ & & \\
\hline \multirow{3}{*}{$\begin{array}{l}\text { Failure to complete } \\
\text { procedure }\end{array}$} & No & 25 & $100.0 \%$ & 25 & $96 \%$ & 24 & $96 \%$ & 4.1 & 0.38 \\
\hline & Adhesions & 0 & $0.0 \%$ & 0 & $0.0 \%$ & 1 & $4 \%$ & & \\
\hline & Obesity & 0 & $0.0 \%$ & 1 & $4 \%$ & 0 & $0.0 \%$ & & \\
\hline \multirow[t]{2}{*}{ Gas leak } & No & 25 & $100.0 \%$ & 23 & $92 \%$ & 25 & $100.0 \%$ & 3.8 & 0.14 \\
\hline & Yes & 0 & $0.0 \%$ & 2 & $8 \%$ & 0 & $0.0 \%$ & & \\
\hline \multirow[t]{2}{*}{ Omental injury } & No & 23 & $92 \%$ & 25 & $100.0 \%$ & 25 & $100.0 \%$ & 3.8 & 0.14 \\
\hline & Yes & 2 & $8 \%$ & 0 & $0.0 \%$ & 0 & $0.0 \%$ & & \\
\hline \multirow{2}{*}{$\begin{array}{l}\text { Major vascular } \\
\text { injury }\end{array}$} & No & 25 & $100.0 \%$ & 25 & $100.0 \%$ & 25 & $100.0 \%$ & NA & NA \\
\hline & Yes & 0 & $0.0 \%$ & 0 & $0.0 \%$ & 0 & $0.0 \%$ & & \\
\hline \multirow[t]{2}{*}{ Bowel injury } & No & 25 & $100.0 \%$ & 25 & $100.0 \%$ & 25 & $100.0 \%$ & NA & NA \\
\hline & Yes & 0 & $0.0 \%$ & 0 & $0.0 \%$ & 0 & $0.0 \%$ & & \\
\hline
\end{tabular}

NA; not applicable, N; number , \%; percent . Chi2 test. 
Table (3) comparison of surgical site infection and seroma between three groups.

\begin{tabular}{|c|c|c|c|c|c|c|c|c|c|}
\hline \multirow[t]{2}{*}{ Parameter } & & \multicolumn{2}{|c|}{ Closed $(n=25)$} & \multicolumn{2}{|c|}{ Open $(n=25)$} & \multirow{2}{*}{$\begin{array}{l}\text { Left upper } \\
(n=25) \\
\text { Number }\end{array}$} & \multirow{2}{*}{$\begin{array}{l}\text { quadrant } \\
\text { Percent }\end{array}$} & \multirow[t]{2}{*}{$\chi^{2}$} & \multirow[t]{2}{*}{$\mathrm{P}$ value } \\
\hline & & Number & Percent & Number & Percent & & & & \\
\hline Surgical site & No & 25 & $100.0 \%$ & 25 & $100.0 \%$ & 23 & $92 \%$ & 4.6 & 0.09 \\
\hline infection & Yes & 0 & $0.0 \%$ & 0 & $0.0 \%$ & 2 & $8 \%$ & & \\
\hline
\end{tabular}

NA; not appilcable, Chi2 test.

Table (4) compariosn of operative time among three groups.

\begin{tabular}{|c|c|c|c|c|c|}
\hline Parameter & $\begin{array}{l}\text { Type of entry } \\
\text { Closed } \\
(n=26)\end{array}$ & Open $(n=26)$ & $\begin{array}{l}\text { Left upper } \\
\text { quadrant }(n=23)\end{array}$ & $\begin{array}{l}\text { Test } \\
\text { statistics }\end{array}$ & $P$ value \\
\hline $\begin{array}{l}\text { Time consumption for entry } \\
\text { (minutes) } \\
\text { (mean } \pm \text { SD) }\end{array}$ & $2.6 \pm 1.2$ & $13.6 \pm 3.1$ & $4.7 \pm 2.9$ & 59.1 & 0.0001 \\
\hline
\end{tabular}

Kruskal wallis test.

Table (5) Pairwise comparison of operative time..

\begin{tabular}{lccc}
\hline Couple & $\begin{array}{c}\text { Close and left upper } \\
\text { quadrant }\end{array}$ & Close and open & $\begin{array}{c}\text { Left upper quadrant } \\
\text { and open }\end{array}$ \\
\hline P value & 1.0 & 0.0001 & 0.0001 \\
\hline
\end{tabular}

Mann Whitney U test.

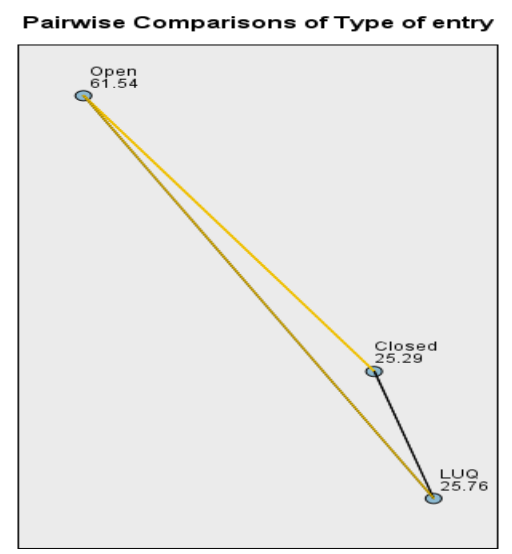

Fig. (1) line chart showing pairwise comparison between study groups.

\section{Discussion}

Closed laparoscopy was associated with mild difficulties in 5.33 percent of cases and serious complications in 1.33 percent of cases, according to the research.

In the open laparoscopy group, $4 \%$ of patients had moderate difficulties, while 0.13 percent had serious issues [11].

A total of 4014 Verres needle cases were studied by Shailesh Kumar and his colleagues [16]. They found abdominal wall emphysema, omental damage, small bowel injury, and mesenteric vascular injury in $(0.050$ percent $)$ of these cases.

In a clinical trial done by Jansen et al., [17], the complication rate was 0.07 percent for the closed approach and 0.17 percent for the open technique.

The open approach had a much greater rate of entry-related problems than the closed technique.
Non-randomized comparison of open and closed laparoscopic entrance by university-affiliated hospital teams was reported by Chapron et al. Only 0.04 percent and 0.01 percent of patients were injured with the closed approach $(\mathrm{n}=8324)$, while the open technique $(\mathrm{n}=1562)$ had no severe bowel or vascular injuries. When it comes to serious difficulties during laparoscopic access, open laparoscopy does not help [18].

There were 594 tissues or organs damaged during laparoscopic access in 566 individuals studied by Chandler et al. [19]. With the open method, they discovered that intestinal injuries were no less prevalent, and that they might still be difficult to detect.

Researchers found that the number of issues associated with the open entrance approach was much 
greater than the number of problems associated with the closed entry strategy.105 [20].

On the other hand, Hasson himself compiled a study of 17 open laparoscopy studies and compared them to studies of closed laparoscopy that comprised 20,691 patients $(669,662$ patients). Gynecologists observed equal complication rates with both the open and the closed procedures, but general surgeons reported greater rates of complications with the closed approach [21].

Open laparoscopy was associated with 0.4 percent of umbilical infection, 0.1 percent of intestinal damage, and 0 percent of vascular injury, according to Hasson. One percent, two percent, and two percent of patients underwent closed laparoscopy, respectively. For general surgeons and gynaecologists, the complication rates for the closed approach were 0.22 percent and 0.04 percent, respectively. It was Hasson's opinion that laparoscopic surgery should be performed using a more traditional open procedure [21].

Hasson's 29-year experience with laparoscopy in 5284 patients yielded just one intestinal damage in the first 50 instances, according to a published record [21].

Laparoscopy should continue to be performed using the closed entrance approach, but patients should still be selected for an open or alternative treatment if necessary" [17].

Closed laparoscopy and open laparoscopy done by gynaecologists were both examined in a separate research by Garry, which included six reports and one survey. There were just 0.04 percent and 0.02 percent rates of bowel and major vessel damage with the closed entrance approach, while there were no major vascular injuries with the open entry. The incidence of intestinal damage was reduced when the survey report $(\mathrm{n}=8000)$ was removed.

With the open approach, the percentage was 0.06 $\%$.'s Following his research, Garry came to the conclusion that open laparoscopy is a viable alternative procedure for avoiding injuries to ordinarily located intra-abdominal structures nearly entirely [5].

A meta-analysis of 760,890 closed laparoscopy and 22,465 open laparoscopy cases found that the incidence of vascular damage was 0.44 percent in closed laparoscopy compared to $0 \%$ in open laparoscopy. Between $0.5 \%$ and $0.7 \%$ of patients were injured in this way, which is a significant difference.

They found that the open (Hasson) approach prevents vascular damage and gas embolism and minimises the risk of intestinal injury and advised that the open technique should be used as the main laparoscopic entrance method [22]

Visceral injuries with closed method ranged from 0.03 percent to 0.15 percent in another research, with the incidence of gastrointestinal tract injuries (80 percent) larger than urinary tract injuries (20 percent) in that study (20 percent ). When using the open approach, the same percentage ranged from $0 \%$ to $0.12 \%$. Delays in diagnosis and treatment were linked with high rates of morality in gynaecological studies (10-50 percent) [20].

Using their general surgery expertise, Bonjer et al. presented a review of the literature on closed and open laparoscopy published up to 1996. Open laparoscopy resulted in no visceral or vascular injuries, whereas closed laparoscopy resulted in 0.08 and 0.07 , respectively [23].

They found that there was no fatal vascular damage, no umbilical infection or herniation related with open laparoscopic entry in 2010, and that the risk of enterotomy was minimal. This technique's ability to quickly identify enterotomies and its usefulness in obese individuals or those who have already had abdominal surgery are further benefits [14].

Open laparoscopy cases from six previously published case series were pooled to create a comprehensive Dutch review of 12,444 instances, which was then analysed across six different case series4, 10-13. Contrast this with 489,335 instances of closed laparoscopic insertions in which the enterotomy rate was $0.083 \%$ and the vascular damage rate was $0.075 \%$ in this same study [14].

There were 22,465 instances from an open laparoscopy series and 760,890 patients from 22 closed laparoscopy series investigated in an Australian metaanalysis. Enterotomies occurred in 0.049 percent of open cases and 0.067 percent of closed cases, according to the researchers (non significant difference). There were no instances of vascular damage in open cases, however there was a statistically significant $(\mathrm{P}=0.003) 0.044$ percent (336 individuals) of vascular injury in closed cases. Using either approach, umbilical infection and hernia rates were comparable [14].

The risk of intestinal damage was 2.17 times greater with open access compared to needle/trocar access in a meta-analysis of gynecologic and general surgical studies.

Because patients with prior abdominal surgery are more inclined to choose open procedures, this might have impacted the study's findings. Non-obese patients, on the other hand, had a $57 \%$ lower risk of mild problems (relative risk $=0.43$ ). Open laparoscopy seems to be preferable than closed entrance when it comes to major adverse events caused by gas insufflation [24].

Out of a total of 21,547 procedures, Molloy et al. reported in a 2002 meta-analysis of laparoscopic entry techniques that the Hasson technique had a 0.1 percent bowel injury rate and a 0.005 percent major vascular injury rate, with the vast majority of reviewed studies only providing level III evidence [25].

Two occurrences $(10 \%)$ of open laparoscopy gas leakage occurred due to the lack of use of a Hasson trocar in the present investigation. early on were controlled by a high gas flow rate $(3 \mathrm{~L} / \mathrm{min})$ and a purse string suture, as well as an in-skin wet gauge. Among 647 open laparoscopies, Pickersgill et al. [26] found gas leakage in fewer than $5 \%$ of instances. 
On the other hand, prior investigations have demonstrated that laparoscopic gynaecological procedures may be safely performed via the left upper quadrant opening. When it comes to laparoscopic surgery, most gynaecologists employ umbilical insufflation, and it seems that the LUQ entrance method may be underused [15].

More than one-third of gynecologic laparoscopies were found to have Palmer's point entrance, with approximately half of these instances being for big uterine fibroids, large ovarian cysts, or prior caesarean birth.

Adhesions between the anterior abdominal wall and the omentum/bowel were found in $22 \%$ of women who had previous obstetrics surgery, and the kind of incision had no effect on this frequency [15].

According to Azevedo et al., Verres needle insertion into the left hypochondrium has been shown to be safe and effective, with less severe side effects. Even so, pinpointing the exact location of the needle after insertion is critical [27]. Prior to insufflation, surgeons may use needle-positioning tests to ensure that the Veress needle is properly positioned for the development of the pneumoperitoneum.

The Veress needle was inserted into the left hypochondrium of 600 morbidly obese individuals by Schwartz et al. [28] to create pneumoperitoneum. One patient's transverse colon was pierced accidently by the muscular layer. Laparoscopic suture was used to close the hole that had been created by the perforation. In addition, no other hollow organs were harmed. An examination of the abdomen revealed no abnormal bleeding, and no damage to the liver or spleen.

The left hypochondrium was punctured 344 times by Rohatgi et al. Peritoneal cavity was reached by just two punctures. Expectant therapy for larger omentum haemorrhage was used as the sole consequence. To create pneumoperitoneum, they found that puncturing the left hypochondrium was the most efficient technique of doing so.

More than one try may be needed to have a needle inserted properly into the left hypochondrium, according to some surgeons [30].

As the Veress needle is inserted in the midline, there is an increased incidence of abdominal wall adhesions when compared to laparoscopy with a transverse incision, as reported by Levrant et al. [31]. It is safe and successful to introduce a hypochondrial Veress needle into the left hypochondrium for the development of pneumoperitoneum.

Despite the widespread use of nasogastric suction, Teoh et al. [32] describe a single incidence of significant gastric damage (3/1000).

None of the 17 instances where the Veress needle was put at Palmer's site resulted in any harm.

In the left upper quadrant, Leonard et al. [34] completed 117 needle insertions without incident. When creating pneumoperitoneum in laparoscopic surgeries, the Veress needle may be inserted into a location other than the midline, such as Palmer's point, the left upper quadrant of belly.

Throughout this investigation, well-trained Consultants executed all of the entrance strategies. As an individual and as an assistant, gynaecological laparoscopic surgeons have more than 8 years of expertise in laparoscopy.

Even in the hands of competent surgeons, significant vascular damage may result from the abdominal midline insertion of the Veress needle.

Only four of the 26 serious vascular injuries were caused by unskilled surgeons, according to Schafer et al (surgeons who had performed fewer than 50 laparoscopic procedures). Eighty-five percent of the injuries were caused either by skilled surgeons (51 surgeries) or very experienced surgeons $(>100$ operations) [36].

Open laparoscopy took longer to enter and generate pneumoperitoneum than closed laparoscopy (mean=2.6 $\mathrm{min}$ ) in the current investigation.

Traditional closed laparoscopy also requires a longer time to enter the left upper quadrant (mean=4.65 minutes).

Instead of open laparoscopy, we found that the typical closed laparoscopy with left upper quadrant entrance quickly identified the intestine after insertion of theVerres needle (mean time14.2 $\mathrm{min}$ ).

On the other hand, a research was published. Incision to cannula insertion took an average of 4 minutes (with a range of 2 to 10). As long as you have the proper training, this treatment may be employed in any case, even if you have had prior surgery [37].

A retrospective assessment of open laparoscopic procedures performed by Hasson from 1970 to 1999 found that access to the abdominal cavity was frequently obtained in 3-10 minutes [1].

Pneumoperitoneum was achieved on average in 2.5 minutes, and the open laparoscopic incision was closed in 4 minutes, according to one research [38].

In open laparoscopy, Gordon found that the median time to establish pneumoperitoneum was 3.5 minutes in 237 individuals [39].

Obesity's effect on surgical results is debatable, especially when it comes to general surgery [40].

Patients with a greater BMI experienced more problems, according to our findings.

Classic closed laparoscopy group (A), open laparoscopy group (B) showed a statistically significant rise in BMI (28.14.8 vs 25.14.87, p=0.058) as compared to group B, however there was no statistically significant increase in BMI in group C (A). There was no significant difference between the typical closed laparoscopy group A and the left upper quadrant entrance group C (28.14.8 vs 28.44.8,p=0.87), however. Due to her obesity, one patient was unable to enter via the LUQ method, since her BMI was 30.

Elective laparoscopic surgery was performed on more than 6300 patients as part of a large cohort study conducted by Dindo and colleagues [41] that was published in the Lancet. Obesity has traditionally been 
linked with an increased surgical risk, but this study revealed no difference in postoperative outcomes between the obese and lean groups.

According to McIlwaine et al. [42], a prospective study of 64 women who had laparoscopy for benign gynaecological conditions, an increase in BMI was linked to more attempts at laparoscopy entry, more difficulty identifying the location of surgical landmarks, and an overall decrease in the planned completion rate of gynaecological laparoscopy operations. In contrast, other research has shown that obese people may safely undergo laparoscopic surgery [40, 43].

The majority of obese patients could have TLH successfully performed with similar complication rates to non-obese patients, according to a second retrospective cohort study by Heinberg [44] on 270 general gynaecology patients, even though operating times and intraoperative blood loss were higher in the obese group.

\section{Conclusion}

With prior abdominopelvic surgery, gaining access to the peritoneal cavity by laparoscopic surgery may be more difficult, time consuming, and even dangerous. This research shows that compared to traditional open laparoscopy, using closed laparoscopy with a left upper quadrant access allows for a faster and safer laparoscopic procedure.

\section{References}

[1] Vilos, A. George. "Laparoscopic entry: a review of techniques, technologies, and complications." Journal of Obstetrics and Gynaecology Canada.vol. 29.5,pp. 433-447,2007.

[2] K.Ülker, T.Anuk, M.Bozkurt, Y.Karasu. Large bowel injury during gynaecological laparoscopy. World Journal of clinical cases.vol.8,pp.846$851,2014$.

[3] Ternamian, Artin. "Laparoscopic entry: a review of Canadian general surgical practice." Canadian Journal of Surgery .vol.54.5,pp. 315,2011.

[4] G.Makai, K.Isaacson. Complications of gynecologic laparoscopy. Clin Obstet Gynecol;vol.52,pp.401-411. ,2009

[5] R. Garry,Towards evidence based laparoscopic entry techniques: clinical problems and dilemmas. Gynaecol Endosc;vol. 8,pp.315$326,1999$.

[6] JF. Magrina Complications of laparoscopic surgery. Clin Obstet Gynecol.;vol.45,pp.469480,2002.

[7] Vellinga, T.Thomas "Laparoscopic Entry: The Modified Alwis Method and More." Rev Obstet Gynecol vol.23,pp.193-198, 2009.

[8] N.Dunne, MI.Booth, TC.Dehn, Establishing pneumoperitoneum: Verres or Hasson? The debate continues. Ann R Coll Surg Engl.vol.93,pp.22-24,2011
[9] J.Mayol, J.Garcia-Aguilar, E.Ortiz-Oshiro, Risks of the minimal access approach for laparoscopic surgery: multivariate analysis of morbidity related to umbilical trocar insertion. World $\mathbf{J}$ Surg.vol.21,pp.529-533,1997

[10] S.Krishnakumar and P.Tambe,"Entry complications in laparoscopic surgery." Journal of gynecological endoscopy and surgery,vol.. 11,pp.4,2009

[11]M.Taye, K.Milan , "Open Versus Closed Laparoscopy: Yet an Unresolved Controversy." Journal of clinical and diagnostic research: JCDR,vol.10.2,pp.04,2016.

[12] G.Ahmad, D.Gent, D.Henderson, Laparoscopic entry techniques. Cochrane Database Syst, vol.8,pp.65-83,2015.

[13] WH.Carlson, G.Tully, A.Rajguru, Cameraless peritoneal entry in abdominal laparoscopy. J Soc Laparoendosc Surg,vol.16,pp.559-563,2012.

[14]L.Long, B.Jaime, "Open laparoscopic access technique: review of 2010 patients." JSLS: Journal of the Society of Laparoendoscopic Surgeons, vol.12.4,pp.372,2008

[15]NGU, FEI.SIEW,TING.CHUNG PUN. "Left upper quadrant approach in gynecologic laparoscopic surgery." Acta obstetricia et gynecologica Scandinavica,vol.90.12,pp.14061409,2011.

[16] K.Shailesh, S.Bhaduri, AM.Ansari, Verres Needle: A safe Technique in Modern Laparoscopic Era. World Journal of Laparoscopic Surgery. vol.6(1),pp.1-5,2013

[17]FW.Jansen, W.Kolkman, EA.Bakkum, Complications of laparoscopy: an inquiry about closed versus open-entry technique. Am J Obstet Gynecol.vol.190,pp.634-638,2004

[18] C.Chapron, L.Cravello, N.Chopin, Complications during set-up procedures for laparoscopy in gynaecology: open laparoscopy does not reduce the risk of major complications. Acta Obstetricia et Gynaecologica Scandinavica. vol.82(12),pp.1125-29,2003

[19] JG.Chandler, SL.Corson, and LW.Way, "Three spectra of laparoscopic entry access injuries," Journal of the American College of Surgeons, vol.192, pp. 478-491,2001

[20] M.Catarci, M.Carlini, and GR.PSEftL Gentileschi. "Major and minor injuries during the creation of pneumoperitoneum." Surgical endoscopy,vol.15.6,pp.566-569,2001

[21] HM.Hasson. Open laparoscopy as amethod of access in laparoscopic surgery.Gynaecol Endosc,vol.8,pp.353-62,1999.

[22] M.Larobina, P.Nottle, Complete evidence regarding major vascular injuries during laparoscopic access.Surg Laparosc Endosc Percutan Tech. vol.15(3),pp.119-123,2005

[23] HJ.Bonjer, "Open versus closed establishment of pneumoperitoneum in laparoscopic surgery." 
British Journal of Surgery,vol.84.5,pp.599602,1997

[24] J.Ott, A.Jaeger-Lansky, G.Poschalko, Gynecol Surg,vol.9,pp.139,2012.

[25] D.Molloy, PD.Kaloo, M.Cooper, Laparoscopic entry: a literature review and analysis of techniques and complications of primary port entry. Aust N Z J Obstet Gynaecol. VOL.42,pp.246-53,2002

[26] A.Pickersgill, RJ.Slade, G.Falconer, Open laparoscopy: the way forward. British Journal of Obstetrics and Gynaecology.vol.106,pp.111619,1999 .

[27] JL.Azevedo, OC.Azevedo, SA.Miyahira, GP.Miguel, Injuries caused by Veress needle insertion for creation of pneumoperitoneum: a systematic literature review. Surg Endosc ,vol.23,pp.1428-1432,2009

[28] ML.Schwartz, RL.Drew, JN.Andersen, Induction of pneumoperitoneum in morbidly obese patients. Obes Surg. vol.13,pp.601-4,2003.

[29]H.Rohatgi and AL.Widdison. "Left subcostal closed (Veress needle) approach is a safe method for creating a pneumoperitoneum," Journal of Laparoendoscopic and Advanced Surgical Techniques A, vol. 14, pp.278-280, 2004.

[30] A.Azevedo, de.Otávio Cansanção, "Veress needle insertion in the left hypochondrium in creation of the pneumoperitoneum." Acta cirurgica brasileira,vol.21.5,pp.296-303,2006

[31] SG.Levrant, E.Bieber, and R.Barnes, "Risk of anterior abdominal wall adhesions Increase whith number and type of previous laparotomy," Journal of the American Association of Gynecologic Laparoscopists,vol.1, pp.S19,1994.

[32] B.Teoh, R.Sen, J.Abbott. An evaluation of four tests used to ascertain Veres needle placement at closed laparoscopy. J Minim Invasive Gynecol;vol.12,pp.153-8,2005

[33] Chang FH, Chou HH, Lee CL, Extraumbilical insertion of the operative laparoscope in patients with extensive intraabdominal adhesions. J Am Assoc Gynecol Laparosc. ;vol.2(3),pp.335337,1995

[34]F.Leonard, F.Lecuru, E.Rizk, Perioperative morbidity of gynecological laparoscopy: a prospective monocenter observational study. Acta Obstet Gynecol Scand,; vol.79,pp.129134,2000

[35] A.Toro, M.Mannino, G.Cappello, Comparison of Two Entry Methods for Laparoscopic Port Entry: Technical Point of View. Diagnostic and Therapeutic Endoscopy,vol.305428,pp. 7,2012

[36] M.Schäfer, M.Lauper, L.Krähenbühl,Trocar and Veress needle injuries during laparoscopy. Surgical Endoscopy.;vol.15(3),pp.275-80,2001.

[37] LAL, L.Pawan, Open port placement of the first laparoscopic port: a safe technique. JSLS: Journal of the Society of Laparoendoscopic Surgeons, vol.8.4,pp.364,2004
[38] N.Perone,Laparoscopy using a simplified open technique: a review of 585 cases. J Reprod Med. vol.37(11),pp.921-924,1992.

[39] S.Gordon, P.Maher, E.Seman, Open laparoscopy utilizing either a $5 \mathrm{~mm}$ or $10 \mathrm{~mm}$ standard intraumbilical trocar. Gynaecol Endosc ,vol.10(4),pp.249-252,2001

[40] L.Joel , A.Pascal , R.Francesco, The Impact of Obesity on Technical Feasibility and Postoperative Outcomes of Laparoscopic Left Colectomy. Ann Surg. Jan;vol.241(1),pp.69-76, 2005.

[41]D.Dindo, MK.Muller, M.Weber, Obesity in general elective surgery. Lancet. vol.361,pp.2032-2035,2003.

[42] K.McIlwaine, "The effect of patient body mass index on surgical difficulty in gynaecological laparoscopy." Gynecological Surgery,vol.8.2,pp.145-149,2011.

[43] M1.Camanni , L.Bonino , EM.Delpiano , G.Migliaretti Laparoscopy and body mass index: feasibility and outcome in obese patients treated for gynecologic diseases. J Minim Invasive Gynecol. vol.17(5),pp.576-82,2010

[44]EM.Heinberg, Crawford BL, Weitzen SH et al. Total laparoscopic hysterectomy in obese versus non-obese patients. Gynecol.vol.103(4),pp.674-680,2004 